\title{
IN-PLANE STIFFNESS OF TRADITIONAL TIMBER FLOORS STRENGTHENED WITH CLT
}

\author{
Jorge M. Branco, Milos Kekeliak, Paulo B. Lourenço \\ ISISE, University of Minho, Department of Civil Engineering, Guimarães, Portugal
}

\begin{abstract}
Five full-scale timber floors were tested in order to analyze the in-plane behaviour of these structural systems. The main objective was to assess the effectiveness of the in-plane strengthening using cross laminated timber (CLT). For that, one unstrengthened specimen (original), one specimen strengthened with a second wood board, two specimens strengthened with 3 CLT panels and one specimen strengthened with 2 CLT panels were tested. Moreover, because of its importance in the composite behaviour, the first phase of the experimental program was composed by push-out tests on specimens representing the shear connection between the timber beams and the CLT panels. This paper describes the tests performed and the numerical modelling aimed to evaluate the composite behaviour of the strengthened timber floors.
\end{abstract}

KEYWORDS: experimental evaluation, in-plane stiffness, strengthening, connection.

\section{INTRODUCTION}

In many countries, traditional construction comprises timber floor and roof systems. Current knowledge assumes the need to preserve and to protect existing timber systems as a cultural value with important advantages to the overall behaviour of the building. Strengthening and stiffening of old timber floors are often needed as they were designed to bear moderate loads and may suffer from excessive in-plane and out-of plane deflections with respect to current requirements. The structural refurbishment of traditional timber floors can be achieved, in order to increase the bending stiffness of the main elements, by including other elements, such as a concrete slab, or timber planks. The structural behaviour of the resulting timber composite structure is governed by the strength and stiffness of the mechanical joints adopted to connect the existing timber beams to the new element.

Another important aspect to be keenly considered is the timber floor diaphragm in plane stiffness, which may affect the structural performance of a traditional masonry building subjected to lateral loads: the common configuration of existing timber floors with a crossly arranged single layer of wooden planks could possibly need an in plane shear strengthening, in order to assure an efficient redistribution of lateral seismic load through the bearing walls $[1,2,3]$.

Several techniques exist to strength timber floors, with different effectiveness in terms of in-plane stiffness [4,5]. One possibility is the use of cross laminated timber (CLT). This wood based material is easy to apply and has mechanical properties with high potential to flexural and in-plane strengthening. In both cases, the connection between the timber beams and the CLT is crucial for the load capacity and distribution of stresses along the floor cross-section. Therefore, in the first research step, an experimental campaign of push-out tests was defined to study the connection between timber beams and CLT elements, using different screws. The main objective was to assess the load-slip behaviour of the connection to allow a full and detailed analysis of the results obtained from the tests of full-scale timber floors done in the following stage. A total of 20 connections were tested divided in four groups, with 5 specimens each, according to the screw used and with their inclination in relation to the shear direction: HBS 8x140 and VGZ 7x140 placed normal to the shear plane and inclined $45^{\circ}$ SFS WT-T-8.2x190 and VGZ 7x180. Then, full-scale timber floors were tested in order to analyze the in-plane behaviour of traditional timber floors and to assess the effectiveness of the CLT-strengthening. Five specimens were tested: one unstrengthened, one strengthened with a second wood board; one strengthened with CLT divided in two panels and two strengthened with CLT divided in three panels. Last two type of specimen were defined to assess the influence of the number of CLT panels used in the strengthening. 


\section{EXPERIMENTAL CAMPAIGN}

\subsection{TEST PROCEDURE AND SPECIMENS}

\subsubsection{TIMBER-TO-CLT PUSH OUT TEST}

A total of 20 timber-to-CLT connections were tested divided in four groups of 5 specimens each, according to the screw used and its inclination with the shear direction: HBS 8x140 and VGZ 7x140 placed normal $\left(90^{\circ}\right)$ to the shear plane and inclined $45^{\circ}$, SFS WT-T-8.2x190 and VGZ 7x180. The central element is made of C24 [6] solid wood with $100 \times 200 \mathrm{~mm}^{2}$ while the exterior ones are made of CLT with $66 \mathrm{~mm}$ thickness.

The main objective of these tests was to assess the shear stiffness of the connections used in the full-scale timber slabs analyzed in the next research step. By using screws placed with different inclination in relation with the shear plane, namely, $90^{\circ}$ and $45^{\circ}$, it was possible to quantify the improvement expected by using screws $45^{\circ}$ inclined, enlarged in the case of full threaded screws. Besides, two types of threaded screws were considered (SFS-WT-T and VGZ) aiming to compare their efficiency.

The load-carrying capacity and the deformation behaviour of the connections were determined by push-out tests according to EN 26891:1991 [7]. During the test, the load and relative displacements (slip deformation) of the joint members were measured. Load was applied with a hydraulic jack and recorded by means of a load cell. To measure the slip deformations two transducers with the accuracy of $0.1 \mathrm{~mm}$ were used.

Fig. 1 shows the specimens of each group where the geometry of the connections and the position of the screws is visible.

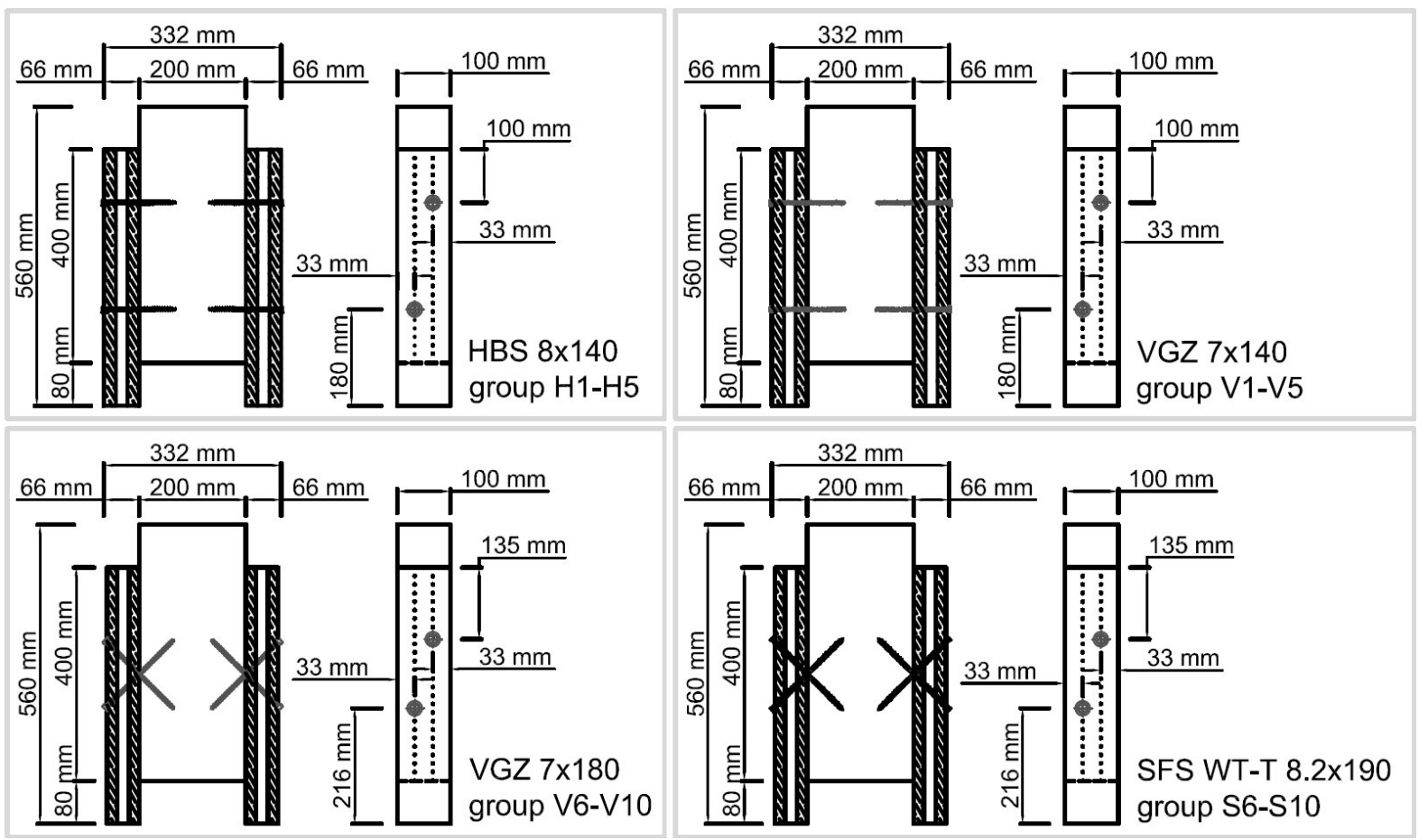

Fig. 1. Specimens used in the push-out tests

\subsubsection{TESTS ON FULL-SCALE TIMBER FLOORS}

Five full-scale timber floors were tested: one unstrengthened floor $(\mathrm{S})$, one floor strengthened with a second wood board (SS); two floors strengthened with three CLT panels (CLT3.1, CLT3.2) and one floor strengthened with two CLT panels (CLT2). Last three type of specimen were defined to assess the influence of the number of CLT panels used in the strengthening and type of used screws. In specimen (S) and (SS), with one and two layers of floorboards, respectively, nails of $2.5 \times 60 \mathrm{~mm}$ were used in the application of the floorboards. In specimens strengthened with CLT CLT2, CLT3.1 and CLT3.2 - screws were used to connect the CLT panels to the timber beams. CLT2 and CLT3.1

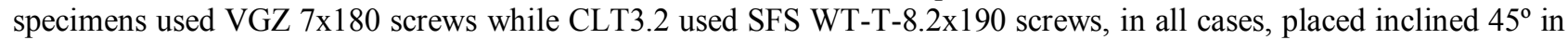
relation to the shear plane. A total of sixty screws, what is thirty joints with X positioned couples of screws, were used for connection of CLT panels to timber beams in each specimen. Fig. 2 presents the timber floors specimens tested. 

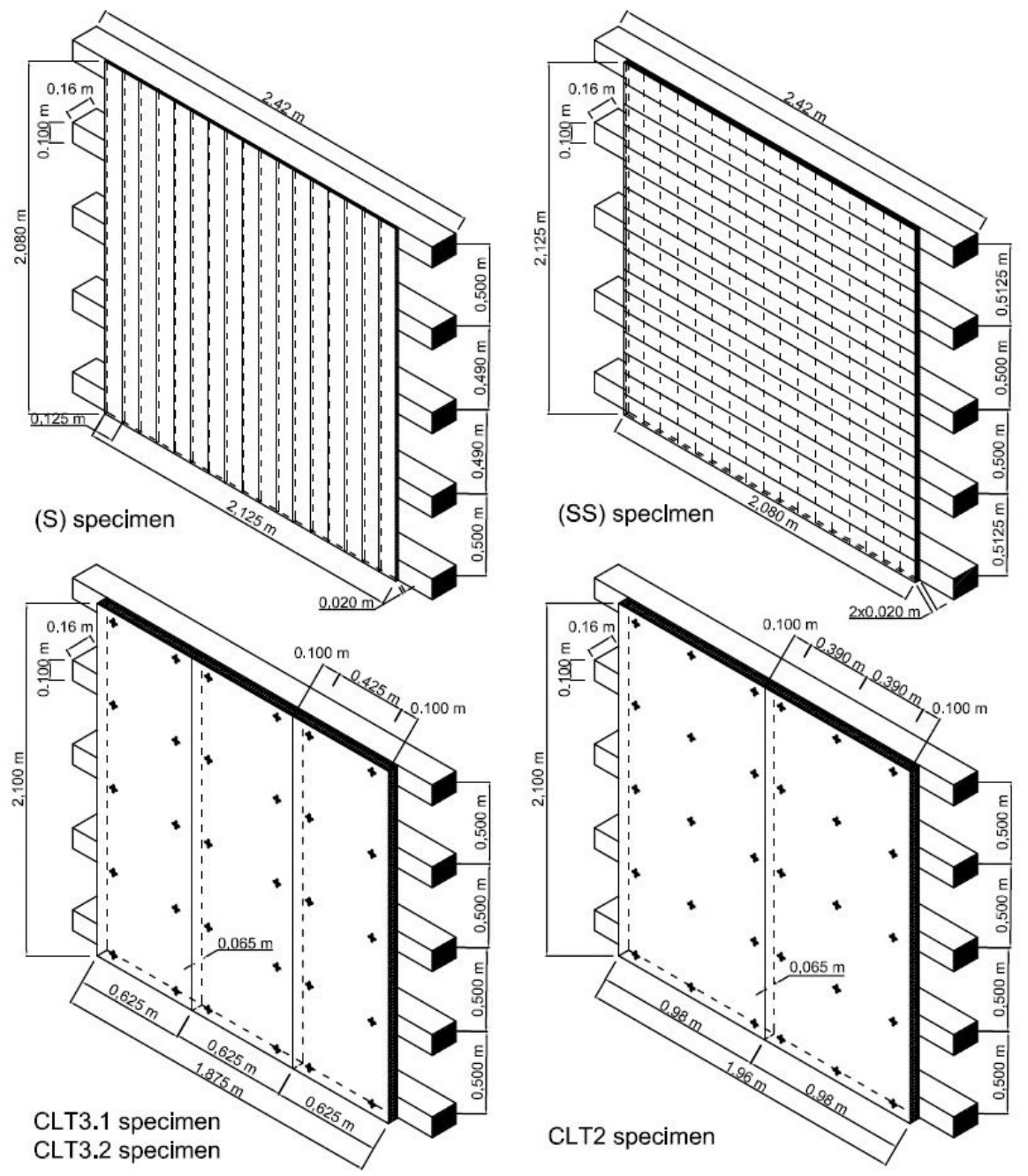

Fig. 2. Specimens used in the full-scale timber floor tests

The test setup is visualized in Fig. 3. A hydraulic jack, positioned at a height of $2 \mathrm{~m}$ above base of the floor, apply a transversal force, with a programmed displacement. In this case, the loading (displacement) was monotonic with a constant rate of $0,05 \mathrm{~mm} / \mathrm{s}$. Seven LVDT sensors have been used for measuring the displacements on the specimens. In Fig. 3, the measuring positions are marked by numbers from 1 to 7 . The force (F) versus displacement (d) curves were measured on positions 1-7 for evaluation of the stiffness behaviour and verification of deformed shape of whole specimens. Central set-up of LVDT sensors, consisting of measuring positions from 4 to 7 , is aligned to the axis of the central beam and to middle of the beam length.

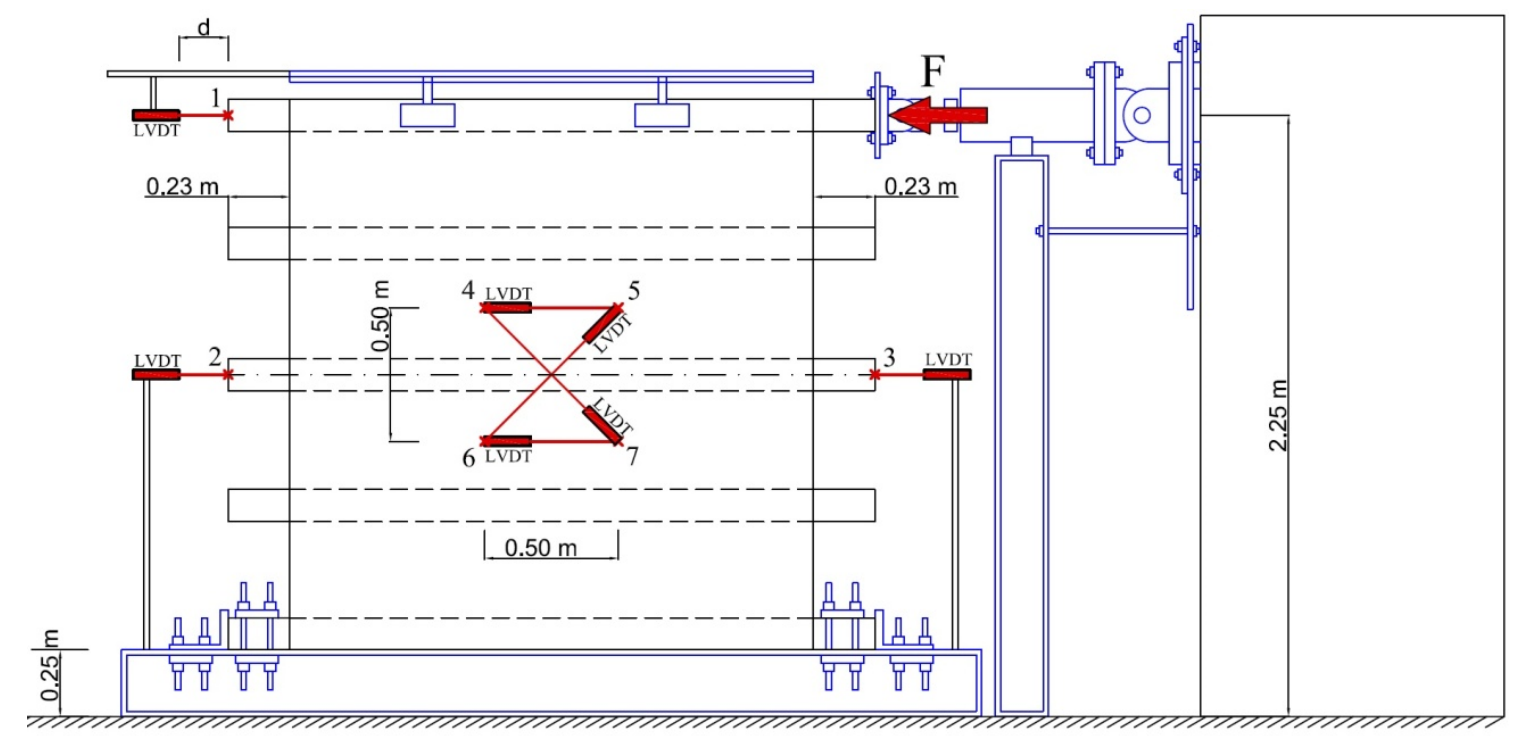

Fig. 3. Setup of the full-scale timber floor tests 


\subsection{TEST RESULTS AND ANALYSIS}

\subsubsection{TIMBER-TO-CLT PUSH OUT TESTS}

The experimental load-slip curves of the timber-to-CLT connections analyzed are presented in Fig 4. The specification of push-out tests and averaged values of numerical characteristics of connections obtained in push-out tests are presented in Table 1. The comparison of the same type of screws VGZ, the specimens group V1-V5 with $90^{\circ}$ inclination angle of screws and group V6-V10 with $45^{\circ}$ inclination angle of screws, the increase of the load carrying capacity is more than $200 \%$ and the increase of the stiffness more than $500 \%$, when the length of screws is not considered. As it was expected, the performance of the SFS type screws in specimens group S6-S10 is higher than in case of screws VGZ in specimens group V6-V10, due to bigger diameter. Considering the load carrying capacity, the displacements and failure modes of connections obtained during the test, the ductile behaviour of screw connections in each specimen group was observed. Mentioned before, the load-carrying capacity and the deformation behaviour of the connections were determined according to EN 26891:1991 [7], where the value of $F_{\text {est }}$ was assumed as the average of the maximum load $F_{\max }$ measured in particular specimen group. The maximum load $F_{\max }$ of each test, corresponds to maximum load measured during the test phase of displacement within $0-15 \mathrm{~mm}$. In general, the inclination angle of the screws had a crucial influence on stiffness and load carrying capacity of connections, investigated in push-out tests. It is recognized, that the value of $\mathrm{K}_{s e r}$ according to EC5 [8] is very low in comparison with tests values. The effective diameter $d_{\mathrm{ef}}$ defined by [8] as the value equal to 1,1-times of core diameter of the screw, was used for calculation of SLS slip modulus $\mathrm{K}_{\mathrm{ser}}$. The effective diameter $\mathrm{d}_{\mathrm{ef}}$, was used for calculation of slip modulus of screw connections in analysis of inclined screws in [9]. The assessment of the SLS slip modulus for connections with $45^{\circ}$ inclination angle of screws was based on the paper [9], wherein the theoretical calculation of connections with inclined screws was performed and the equation (1), (2), (3), (4) were used and derived.

$$
\begin{aligned}
& \mathrm{K}_{s e r}=K_{\perp} \cdot \cos ^{2} \alpha+K_{I I} \sin ^{2} \alpha \\
& \mathrm{K}_{I I}=\frac{1}{1 / K_{s e r, a x, 1}+1 / K_{s e r, s a x, 2}} \\
& \mathrm{~K}_{I I}=\mathrm{K}_{s e r, a x, i} \\
& \mathrm{~K}_{s e r, a x, i}=30 . s_{g} \cdot d
\end{aligned}
$$

Where $\alpha$ is the inclination angle of the screw, $K \perp$ is SLS slip modulus according to [8] for one screw and one shear plane, $K_{I I}$ is the axial slip modulus for a screw, Eq. (2) for the double stiffness model; Eq. (3) for the single stiffness model, $K_{s e r}$ is the stiffness for screws crossed in an X position working simultaneously one under shear-tension stress and the other under shear-compression stress, $K_{s e r, a x, i}$ is the instantaneous withdrawal/penetration stiffness, $s_{g}$ is the embedment length, in $\mathrm{mm}$, of the threaded segment of the screw and, $d$ is the outer diameter of the screws thread.

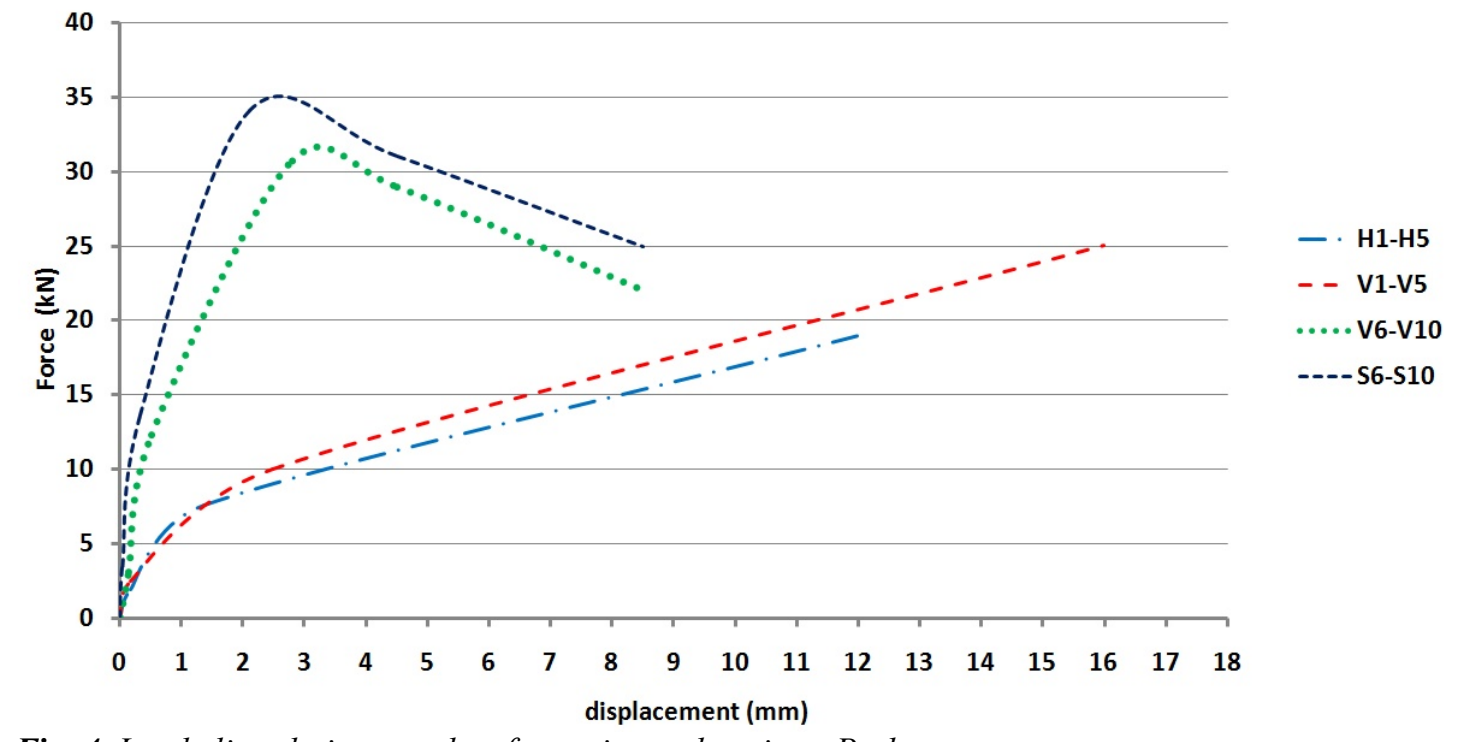

Fig. 4. Load-slip relation, results of experimental testing - Push-out tests 
Table 1. Stiffness of screw connections - average results of experimental testing - Push-out tests

\begin{tabular}{|c|c|c|c|c|c|c|c|c|c|c|c|c|}
\hline \multirow{3}{*}{$\begin{array}{l}\text { Specimen } \\
\text { group }\end{array}$} & \multirow{3}{*}{$\begin{array}{c}\text { Type of } \\
\text { screw } \\
\\
\text { Reference } \\
\text { Ø-Length }\end{array}$} & \multicolumn{3}{|c|}{$\begin{array}{c}\text { Maximum force } \\
\text { reached } \\
\text { (experiment) }\end{array}$} & \multirow{2}{*}{\multicolumn{2}{|c|}{$\begin{array}{c}\begin{array}{c}\text { Load carrying } \\
\text { capacity }\end{array} \\
\begin{array}{c}\text { EN 1995-1- } \\
1: 2004\end{array}\end{array}$}} & \multicolumn{6}{|c|}{ SLS slip modulus $K_{\text {ser }}$} \\
\hline & & \multicolumn{2}{|c|}{$\begin{array}{c}\text { Specimen } \\
4 \text { screws }\end{array}$} & \multirow{2}{*}{$\begin{array}{c}1 \\
\text { screw } \\
\\
\text { F }_{\max } / 4 \\
(\mathrm{kN})\end{array}$} & & & \multicolumn{3}{|c|}{ Experimental } & \multirow{2}{*}{$\begin{array}{c}\text { EC5 } \\
\\
1 \\
\text { screw }\end{array}$} & \multicolumn{2}{|c|}{$\begin{array}{c}\text { Stiffness according } \\
\text { to }[9]\end{array}$} \\
\hline & & $\begin{array}{l}\mathbf{F}_{\max } \\
(\mathbf{k N})\end{array}$ & $\begin{array}{l}\mathrm{COV} \\
(\%)\end{array}$ & & $\begin{array}{c}\text { Failure } \\
\text { mode }\end{array}$ & $\begin{array}{l}\mathrm{F}_{\mathrm{vRk}} \\
(\mathrm{kN})\end{array}$ & $\begin{array}{c}\text { one } \\
\text { shear } \\
\text { plane } \\
2 \\
2 \\
\text { screws }\end{array}$ & $\begin{array}{c}1 \\
\text { screw }\end{array}$ & $\begin{array}{l}\text { COV } \\
(\%)\end{array}$ & & $\begin{array}{c}\text { Single } \\
\text { stiffness } \\
\text { model } \\
1 \text { screw }\end{array}$ & $\begin{array}{c}\text { Double } \\
\text { stiffness } \\
\text { model } \\
1 \text { screw }\end{array}$ \\
\hline H1 - H5 & HBS $8 \times 140$ & 19,01 & 8 & 4,75 & $\mathrm{f}$ & 5,48 & 2738 & 1369 & 42 & 2419 & - & - \\
\hline V1 - V5 & VGZ 7x140 & 25,05 & 11 & 6,26 & $\mathrm{f}$ & 4,22 & 1917 & 959 & 43 & 2060 & - & - \\
\hline V6 - V10 & VGZ 7x180 & 30,73 & 5 & 7,68 & $\mathrm{f}^{*}$ & 5,08 & 12376 & 6188 & 15 & - & 8165 & 4598 \\
\hline S6 - S10 & SFS $8.2 \times 190$ & 34,09 & 16 & 8,52 & $\mathrm{f}^{*}$ & 6,85 & 18642 & 9321 & 23 & - & 9626 & 5429 \\
\hline
\end{tabular}

f* - failure mode (f) according to EC1995-1-1:2004 was observed simultaneously with failure related with the withdrawal capacity of the screw

\subsubsection{FULL-SCALE TIMBER FLOORS}

As mentioned before, five full-scale specimens were tested to analyze the in-plane behaviour of timber floors and the effectiveness of the CLT-strengthening. The specimen (S) represents an unstrengthened timber floor, with timber beams and floorboards only. The specimen (SS) is strengthened by a second layer of floorboards placed orthogonal to the first and specimens CLT3.1, CLT3.2, CLT2 represent the strengthening method based in the use of CLT panels connected to timber beams by screws according to the provisions specified in Table 2 . The specimens evaluated can be divided in two main groups: specimens with floorboards and specimens with CLT panels. The maximum load $F_{\max }$ of each test corresponds to maximum load measured during the test phase of displacement within $0-100 \mathrm{~mm}$. The stiffness $K$ was evaluated according to EN 26891:1991 [7], where the value 0,4.F est and 0,1.F est were assumed to be equal to $0,4 . F_{\max }, 0,1 . F_{\max }$ respectively, and the corresponding displacements $v_{0,4}, v_{0,1}$ were used in calculation. For calculation of the stiffness $K$ of the timber floors, the force applied on upper beam and displacement on the opposite side of the beam was used. Tests results obtained point out that strengthening using a second layer of floorboards (specimen SS) can double the stiffness of the timber floor system (specimens S), while the ultimate resistance has been increased almost to a quadruple value. The specimens strengthened by CLT panels are approximately $5-10$ times stiffer than the unstrengthened specimen (S) and 2-4 times stiffer than specimen strengthened by a second layer of floorboard (specimen SS). Experimental results show that specimens with CLT divided in three CLT panels were 30\% stiffer than specimen strengthened with 2 CLT panels. The highest stiffness was observed on specimen CLT3.2, where the SFS type of screw with bigger diameter was used. The results of stiffness and ultimate resistance of timber floor specimens obtained during experimental testing are presented in Fig. 5 and Table 2.

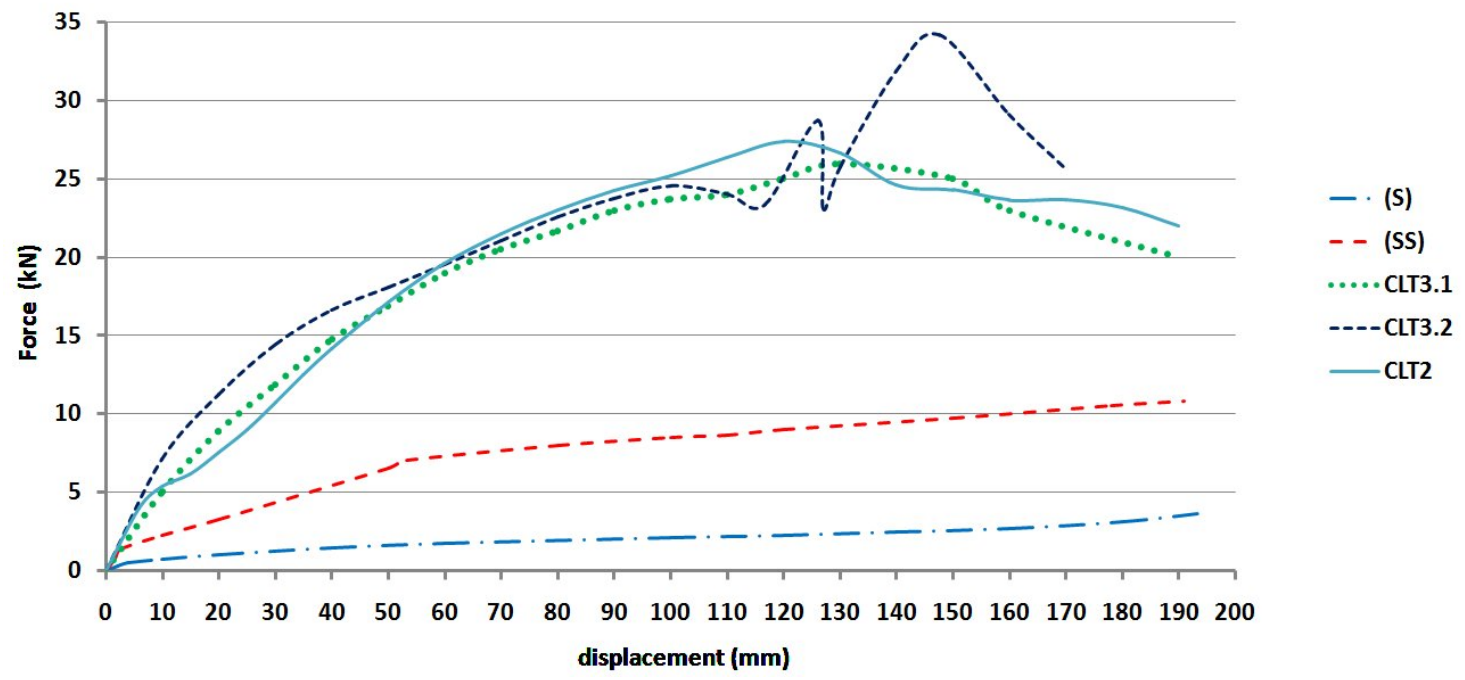

Fig. 5. Load slip behaviour of the full-scale timber floors 
Table 2. Stiffness and ultimate strength - results of experimental testing - Timber floor tests

\begin{tabular}{|c|c|c|c|c|c|}
\hline $\begin{array}{c}\text { Specimen } \\
\text { label }\end{array}$ & Specimen description & \multicolumn{2}{|c|}{$\begin{array}{c}\text { Description of } \\
\text { connection } \\
\text { Number of fasteners / } \\
\text { joint }\end{array}$} & $\begin{array}{c}\text { Maximum } \\
\text { force } \\
\text { reached } \\
\mathbf{F}_{\mathbf{m a x}} \\
\mathbf{~ k N ~})\end{array}$ & $\begin{array}{c}\text { Stiffness } \\
\text { of } \\
\text { specimen } \\
\mathbf{K} \\
\text { ( N/mm })\end{array}$ \\
\hline (S) & One layer of floorboards & 2 nails & $2,5 \times 60$ & 2,13 & 55 \\
\hline (SS) & Two layers of floorboards & 4 nails & $2,5 \times 60$ & 8,51 & 132 \\
\hline CLT3.1 & Three CLT panels & 2 screws & VGZ 7x180 & 23,70 & 411 \\
\hline CLT3.2 & Three CLT panels & 2 screws & SFS $8.2 \times 190$ & 24,55 & 563 \\
\hline CLT2 & Two CLT panels & 2 screws & VGZ 7x180 & 25,20 & 311 \\
\hline
\end{tabular}

\section{NUMERICAL MODELLING}

The numerical analysis and study of structural behaviour of timber floor specimens was performed in order to evaluate its composite behaviour. Numerical models were developed in finite element analysis (FEA) software ANSYS [10]. Considering the capability of the finite elements, the structural models of timber floor specimens were assumed to be modelled with use of one dimensional (1D) beam elements and volume solid elements. 1D beam elements BEAM188 were used for modelling timber beams in floor specimens, and volume elements SOLID186 were used for modelling of CLT panels. The CONTA174/TARGE170 elements were used for modelling of contact interface and related friction between elements representing the CLT panels. The eccentric position of timber beams to CLT panels was neglected and the position of the beam elements was assumed to be in the middle plane of CLT element. The structural system in numerical model was fixed by three vertical supports and one horizontal support on the bottom beam, and horizontal supports in direction out of plane of floor in each connection between the beams and CLT panels. Structural members in numerical models, the beams and CLT panels, respected dimensions of timber floor specimens. Description of numerical models is presented in Fig 6.

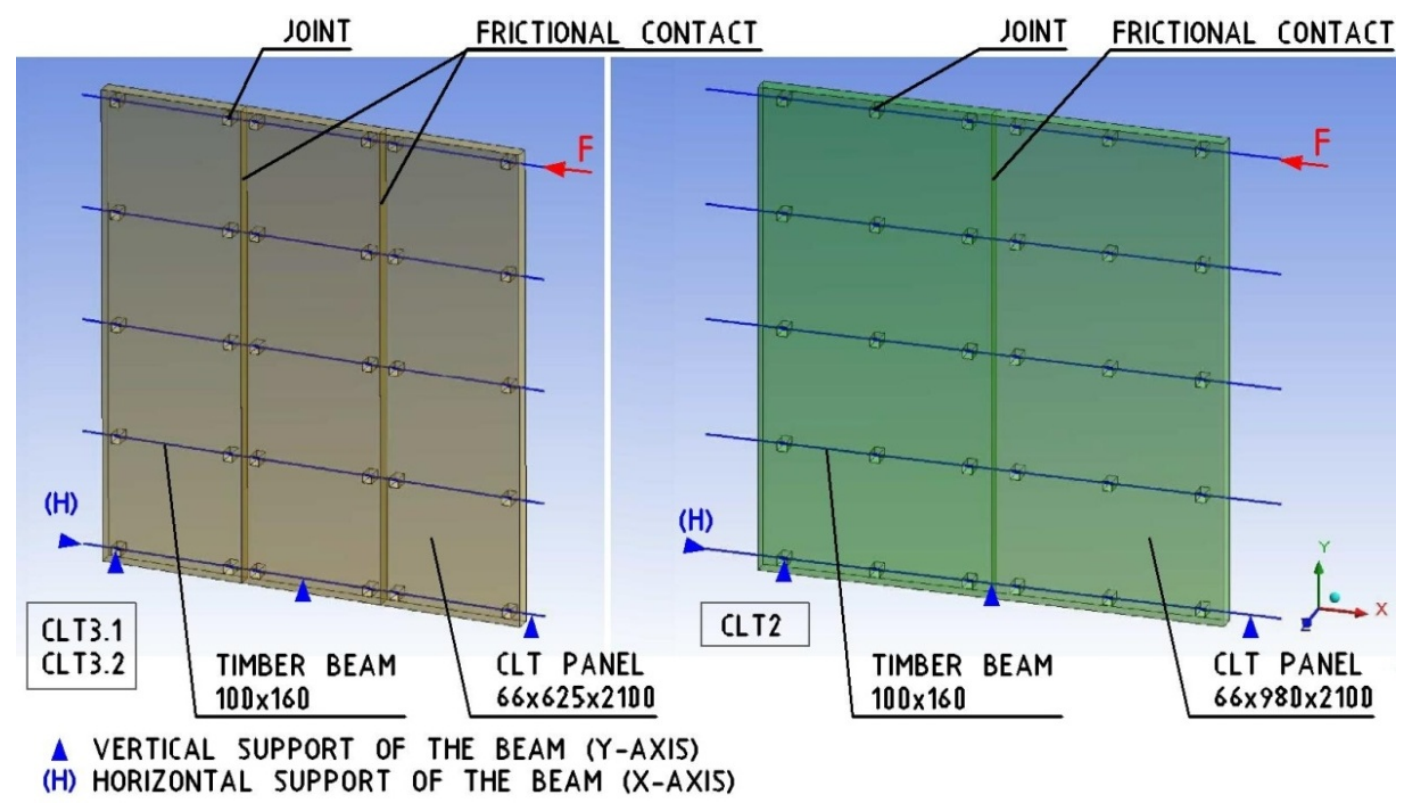

Fig. 6. Description of numerical models of timber floors specimens CLT3.1, CLT3.2, CLT2

Connections between beam elements and volume elements (timber beam - CLT panel) have been modelled with use of MPC184 elements with linear force-displacement relation in two directions in plane of CLT, considering the slip modulus $\mathrm{K}_{\text {ser }}$ achieved by the push-out tests performed. The $\mathrm{K}_{\text {ser }}$ value of HBS8x140 screws from push-out tests (group V1-V5) was used for load-slip relation in direction perpendicular to the beam axis, in joints for numerical model of CLT3.2. The third displacement, orthogonal to the CLT plane was considered fixed. All rotational degree of freedom, in the three axes, were release. A simplified description of the in-plane structural behaviour of timber floor as the 
composite of CLT panels and timber beams is showed in Fig. 7, where the rigid connection of fastener to beam is assumed and slip on CLT is described. Considering the global displacement shape of timber floor, it can be expected, that the stiffness of the connection in direction perpendicular to the axis of the beam affects the stiffness more strongly than the connection stiffness in direction parallel to the axis of the beam.

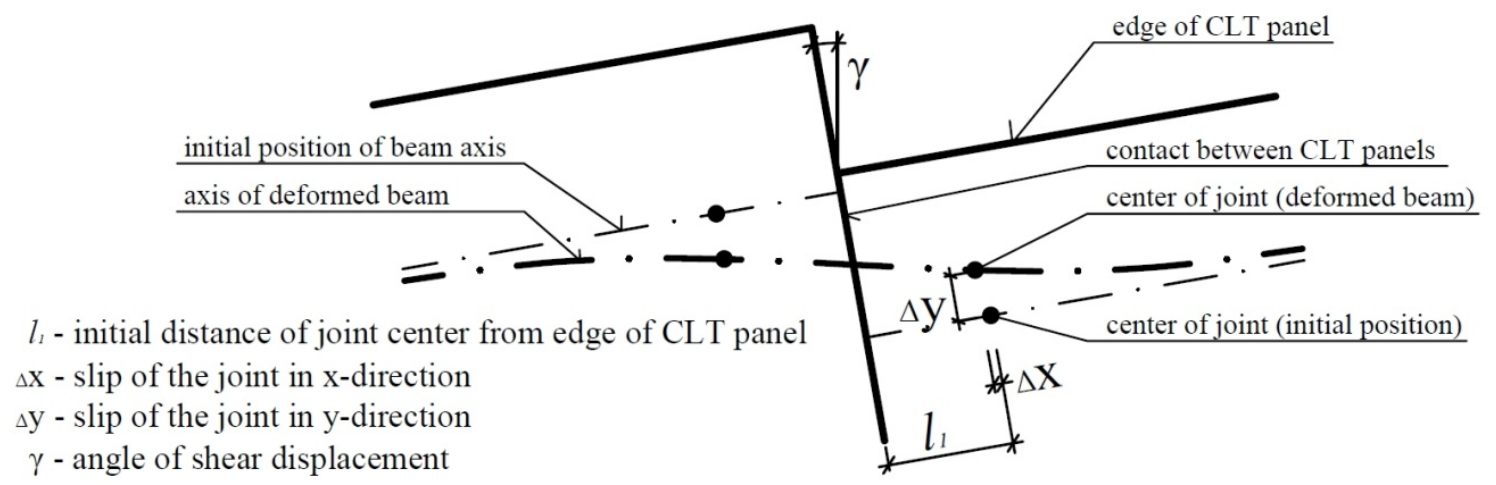

Fig. 7. Shear displacement between CLT panels; slip in screw joint

Taking into account the anisotropy of wood, transversely isotropic material model was defined in the three orthogonal directions, where properties in radial and tangential direction were assumed to be equal because of reduction of material characteristics. In terms of material properties, the elastic material characteristics of C24 defined in standard EN 338 [6] were adopted for the beam elements. The poisson's ratios $v_{\mathrm{LT}}$ and $v_{\mathrm{RT}}$ were calculated based on [11] and missing mechanical parameters were obtained as depended mechanical properties for transversely isotropic model. Material characteristics of CLT panels were adopted and modified, based on EN 338 [6] and European Technical Approval ETA-06/0009 [12]. The boards in particular layers of the CLT panels were graded by manufacturer to strength class C24 [6]. Mentioned before, material characteristics of CLT panels were modified in order to respect and approximate the stiffness behaviour of the CLT panel, influenced by different orientation of timber boards in particular layers of CLT. Elastic properties were calculated as weighted average of material characteristic of wood for parallel and perpendicular to the grain direction respecting the thickness of corresponding layers of CLT panel. It is necessary to note, that shear stiffness in RT-plane for CLT material property is significant higher than the value provided by technical list, due to dependency of material characteristics for material model used, but without the influence on simulation, when considering the centred position of the beam elements and in-plane direction of the load. As it was observed during the tests, the stiffness behaviour of whole specimens was influenced particularly by stiffness of the screw connections, because of this fact, the material model used and the simplification of the CLT panel as one anisotropic timber member, were assumed as a proper approach for simulation of timber floor tests. The summary of the material characteristics of timber floor members are presented in Table 3.

Table 3. The summary of mechanical properties of timber member in numerical models

\begin{tabular}{|c|c|c|c|c|c|c|c|c|c|}
\hline Mechanical parameter & $\stackrel{\bigcup}{\varrho}$ & a & 뵈 & $\begin{array}{c}\text { 푀 } \\
\| \\
\text { |c工 }\end{array}$ & $\begin{array}{l}\vec{x} \\
\vec{v} \\
\vec{v}\end{array}$ & $\bar{v}$ & 5 & $\overrightarrow{\underline{x}}$ & $\stackrel{\bar{x}}{\bar{\nu}}$ \\
\hline Type of timber member & $e^{\circ}$ & 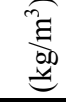 & $\stackrel{\overparen{E}}{\sum^{E}}$ & $\stackrel{\Xi}{\varrho}$ & $\sum^{\overparen{E}}$ & $\sum^{\Theta}$ & ' & 1 & 1 \\
\hline Timber strength class C24 ${ }^{(1)}$ & 12,0 & 420 & 11000 & 370 & 690 & - & - & - & - \\
\hline CLT board - strength class C24 (2) & 12,0 & 470 & 11000 & 370 & 690 & 50 & - & - & - \\
\hline Timber beams (numerical model characteristics) & - & - & 11000 & 370 & 690 & 128 & $0,440^{(3)}$ & 0,015 & $0,450^{(4)}$ \\
\hline CLT panel (numerical model characteristics) & - & - & 7492 & 3878 & 690 & 1337 & $0,440^{(3)}$ & 0,227 & $0,450^{(4)}$ \\
\hline
\end{tabular}

MOC - Moisture content, $\rho_{\mathrm{m}}$ - Mean density, E - Elastic modulus, G - Shear elastic modulus, L - Longitudinal direction, R - Radial direction, $\mathrm{T}$ - Tangential direction, $v$ - poisson's ratio

1 - material properties used from the European standard EN_338 [6]

2 - material properties used from the European technical a approval Binderholz, ETA-06/0009 [12]

3 - value obtained as geometric average of poisson's ratios $v_{\mathrm{LT}}$ and $v_{\mathrm{LR}}[11]$

4 - value obtained as geometric average of poisson's ratios vRT and vTR [11]

The parametric study by means of finite element modelling was performed in order to investigate composite behaviour of timber floor specimens. For each specimen, CLT3.1, CLT3.2, CLT2, three groups of numerical models were developed, depended on variation of the stiffness characteristics of screw connections and friction between the 
CLT panels. The influence of friction between CLT panels on stiffness behaviour of timber floor specimen was analyzed by variation of coefficient of friction in numerical models. For each specimen three numerical models were developed, where the coefficient of friction $\mu$ varied in range of $0,2-0,8$.

\section{RESULTS AND DISCUSSION}

The results of experimental testing and numerical modelling show the relation between structural members and its connection. The variation of stiffness characteristics of screw connections, the values of coefficient of friction used and results of numerical modelling are presented in Table 4. Comparison of results of experimental testing and numerical modelling shows good match in case of CLT3.1 and CLT3.2 specimens. In case of specimen CLT2, the stiffness behaviour obtained by means of numerical modelling was overestimated. This can be explained by simplified modelling of connection, where only linear load-slip relation was used in numerical models. Because of this simplification, the structural behaviour of elastic phase is considered in comparison. The results of parametric study shows, that the main influence on in-plane stiffness of whole timber floor specimens had the stiffness behaviour of the screw connections in the direction perpendicular to the axis of the beams. The influence of the friction between the CLT panels was not observed as a significant factor of global stiffness of timber floor specimens. As it was presented in results of push-out tests, the inclination angle had major influence on stiffness and load-carrying capacity of joints. Considering this influence on local joint and composition of structural members into whole structure, the global behaviour of composite structure can be significantly changed depending on connection applied, or modified as required.

Table 4. Specification of numerical models and results of numerical modelling

\begin{tabular}{|c|c|c|c|c|c|c|c|c|c|}
\hline Model name & 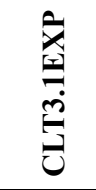 & 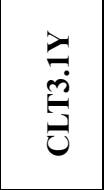 & $\frac{x}{\vec{m}}$ & 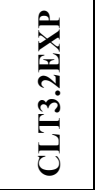 & 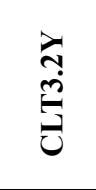 & 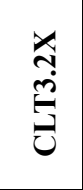 & 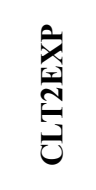 & 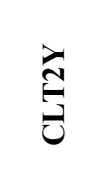 & 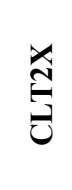 \\
\hline $\mathrm{K}_{\text {ser }}(\mathrm{N} / \mathrm{mm})$, SLS Slip modulus in X-direction & 12376 & 12376 & 1917 & 18642 & 18642 & 2738 & 12376 & 12376 & 1917 \\
\hline $\mathrm{K}_{\text {ser }}(\mathrm{N} / \mathrm{mm})$, SLS Slip modulus in Y-direction & 1917 & 12376 & 1917 & 2738 & 18642 & 2738 & 1917 & 12376 & 1917 \\
\hline $\mathrm{K}(\mathrm{N} / \mathrm{mm})$, Coefficient of friction $\mu=0,2$ & 452 & 2032 & 425 & 623 & 2687 & 589 & 528 & 1990 & 496 \\
\hline $\mathrm{K}(\mathrm{N} / \mathrm{mm})$, Coefficient of friction $\mu=0,5$ & 456 & 2036 & 429 & 626 & 2690 & 593 & 531 & 1993 & 499 \\
\hline $\mathrm{K}(\mathrm{N} / \mathrm{mm})$, Coefficient of friction $\mu=0,8$ & 460 & 2040 & 433 & 629 & 2693 & 597 & 534 & 1996 & 502 \\
\hline $\mathrm{K}(\mathrm{N} / \mathrm{mm})$, experimental testing & 411 & \multicolumn{2}{|c|}{ CLT3.1 } & 563 & \multicolumn{2}{|c|}{ CLT3.2 } & 311 & \multicolumn{2}{|c|}{ CLT2 } \\
\hline
\end{tabular}

CLT_EXP - numerical model with connection stiffness obtained by push-out tests, CLT_Y, CLT_X - numerical model with modified connection stiffness in $\mathrm{Y}, \mathrm{X}$-direction, The orientation of the $\mathrm{X}, \mathrm{Y}$-direction is consistent with directions of $\mathrm{x}$, $\mathrm{y}$-displacements presented in Fig.7, K - stiffness of timber floor specimen obtained as the result of numerical modelling. The same procedure of evaluation was used as used in full scale timber floor test [7].

\section{ACKNOWLEDGEMENT}

The present work is part of a research project supported by program Quadro de Referência Estratégico Nacional (QREN), project number 21635, from the Agência de Inovação (ADI). The authors would like to thank BinderHolz and Rotho Blaas for all the support offered, particularly in the preparation and execution of the experimental program.

\section{REFERENCES}

[1] Branco, J.M., Cruz, P.J.S. and Piazza, M. (2009), Experimental analysis of laterally loaded nailed timber-to-concrete connections. Construction and Building Materials. 23 (1), 400-410.

[2] Dias, T. I. (2008). Pavimentos de madeira em edifícios antigos. Diagnóstico e intervenção. Porto. Dissertação de Mestrado em Engenharia Civil, FEUP. (In Portuguese)

[3] Appleton, J. (2003). Reabilitação de edifícios antigos patologias e tecnologias de intervenção. ORION

[4] Valluzzi, M., Garbin, E., Benetta, M. D., \& Modena, C. (2008). Experimental assessment and modelling of in-plane behaviour of timber floors. SAHC 2008 - Structural Analysis of Historical Constructions, Bath, UK, 02-04 July.

[5] Angeli, A., Piazza, M., Riggio, M., \& Tomasi, R. (2010). Refurbishment of traditional timber floors by means of wood-wood composite structures assembled with inclined screw connectors. 11th World Conference on Timber Engineering - WCTE 2010, 20-24 June 2010, Riva del Guarda, Trentino, Italy.

[6] EN 338:2003, Structural timber - strength classes. European Committee for Standardization, Brussels.

[7] EN 26891:1991, Timber structures. Joints made with mechanical fasteners. General principles for the determination of strength and deformation characteristics. European Committee for Standardization.

[8] EN 1995-1-1:2004 Eurocode 5 - Design of timber structures, Part 1-1: General - Common rules and rules for buildings, Brussels.

[9] Tomassi, R., Crosatti, A., Piazza, M. (2010), Theoretical and experimental analysis of timber-to-timber joints connected with inclined screws. Construction and Building Materials. 24 (2010), 1560-1571.

[10] ANSYS ${ }^{2}$, Academic Research, Release 12.0. (2009), ANSYS, Inc. Documentation for Release 12.0.

[11] Dahl, K.B. (2009), Mechanical properties of clear wood from Norway spruce. Ph.D dissertation, Norwegian University of Science and Technology, Trondheim.

[12] European technical a approval ETA-06/0009. (2011), Multilayered timber elements for walls, ceilings, roofs and special construction components. European Organisation for Technical Approvals. 